\title{
IDENTIDADES MODERNAS DO PLANO URBANO DE GOIÂNIA*
}

\author{
MODERN IDENTITIES OF URBAN PLAN OF GOIÂNIA
}

\section{IDENTIDADES MODERNAS DEL PLAN URBANO DE GOIÂNIA}

\author{
Cristiano Alencar Arrais - Universidade Federal de Goiás - Goiânia - Goiás - Brasil \\ alencar_arrais@yahoo.com.br
}

\begin{abstract}
Resumo
Os estudos urbanos sobre a edificação da cidade de Goiânia encontram diante de si um problema de ordem heurística, pois tomam como verdadeira a ideia de modernidade urbana, sem levar em consideração que as expectativas projetadas nos documentos técnicos não podem ser tomadas como expectativas realizadas. Relatórios e projetos indicam seus vínculos com a modernidade europeia. Há que se perceber, porém, que sua identidade moderna está muito menos associada aos modelos de cidades citadas nas fontes e muito mais nas apropriações realizadas pelos projetistas da nova capital goiana. Por isso é preciso ressaltar que, se numa perspectiva purista as características que destoam do modelo europeu são interpretadas como desequilíbrio, frustração, deturpação e farsa, na verdade elas revelam o caráter plural e potencialmente criativo, capaz de engendrar soluções novas, próprias do processo de modernização brasileiro. São esses elementos que constituem a identidade moderna do plano urbano de Goiânia.
\end{abstract}

Palavras-chave: modernidade, planejamento urbano, urbanismo.

\section{Abstract}

The urban studies on the edification of the city of Goiania are faced with a problem of order heuristics because they take as true the idea of urban modernity without taking into account that the expectations projected in technical documentation cannot be taken as expectations held. Reports and projects indicate their links with European modernity. We must realize, however, that its modern identity is much less associated with models of cities cited in the sources and much more in the appropriations made by the designers of the new capital of Goiás state. Therefore we must emphasize that if in a purist perspective the features that clash with the European model are interpreted like imbalance, frustration, corruption and farce, actually reveal the feature plural and potentially creative, able to engender new solutions, inherent to the process of Brazilian modernization. It is these elements that constitute the modern identity of the urban plan of Goiania.

Keywords: modernity, urban planning, urbanism.

\section{Resumen}

Los estudios urbanos sobre la construcción de la ciudad de Goiania son, enfrentan a un problema de orden heurística porque toman como cierta la idea de la modernidad urbana, sin tener en cuenta que las expectativas proyectadas en la documentación técnica no se puede tomar como expectativas que se tienen. Los informes y proyectos indican sus vínculos con la modernidad europea. Debemos darnos cuenta, sin embargo, que su identidad moderna es mucho menos asociada con los modelos de las ciudades mencionadas en las fuentes y más en las asignaciones hechas por los diseñadores de la nueva capital de Goiás. Por lo tanto, tenemos que destacar que si una perspectiva purista las cuentas que contrastan con el modelo europeo se interpretan como el desequilibrio, frustración, corrupción y farsa, en realidad revelan el caráter plural y potencialmente creativo,

\footnotetext{
* 0 presente artigo é resultado parcial do projeto de pesquisa "Cidades Capitais e Modernidade Urbana: transito de modelos culturais na construção de Goiânia", que conta com apoio da FAPEG (Edital PPP/FAPEG/CNPq 006/2009).
} 
capaz de diseñar nuevas soluciones, propias del proceso de modernización brasileño. Son estos los elementos que constituyen la identidad moderna del plan de Goiania.

Palabras clave: modernidade, planificación urbana, modernidad.

\section{Introdução}

É tema pacífico nos estudos urbanos de Goiás a identificação da construção da nova capital, na década de 1930, como o marco da incorporação do estado na modernidade. Sob um discurso político que buscava sua legitimação mediante a ênfase a uma dicotomia temporal, a nova capital foi apresentada como o símbolo da modernidade, em oposição ao passado de atraso e decadência.

Essa condição sociocultural denominada modernidade foi entendida como uma forma paradoxal de experiência do tempo e do espaço, um "turbilhão de permanente desintegração e mudança, de luta e contradição, de ambigüidade e angústia” (Berman, 1987), e fundamentalmente de aceleração do tempo e distanciamento progressivo entre o espaço de experiência e o horizonte de expectativa. Incapacidade de recordar e transmitir experiência, anacronização e fetichização cultural, racionalização e desencantamento do mundo são apenas algumas de suas principais características (Silva, 1997, p. 22). Ela pode assumir também nuances próprias, de acordo com as relações construídas entre as forças de transformação e de permanência que atuam nesses ambientes.

A opção pelo purismo conceitual, quando da utilização desse termo para a análise da experiência brasileira, reforçou o caráter limitado e forçado da incorporação dos modelos de racionalização de matriz europeia, tendo em vista a necessidade de convivência com formas de sociabilidade que acabaram por ressignificar a condição moderna. E especificamente no caso da construção da nova capital do estado de Goiás, implicou na transformação das expectativas projetadas, encontradas nos documentos técnicos da construção da nova capital, em realizações localizadas naquele campo da experiência. É essa distância entre o horizonte de expectativas dos projetistas e o campo de experiência encontrado que configurou aquilo que podemos chamar de modernidade em Goiânia.

A visão de uma Goiânia moderna encontra respaldo num tipo específico de vestígio que foi deixado à época da construção da nova capital: os relatórios técnicos e os projetos elaborados pelos urbanistas que planejaram a capital goiana. Tais vestígios demonstram a necessidade de refe- 
rencialização, associada a outras experiências de construção de cidades novas, tais como Belo Horizonte, Letchworth, Radburn (cidades-jardins inglesas), Gary, Chicago, Paris, Magnitogorsk, Camberra.

Como sabemos, é próprio do urbanismo realizar esse processo de antecipação do mundo a ser construído. A planificação das necessidades e das funções da sociedade mediante sua projeção no espaço, própria do urbanismo moderno, lembra Roncayolo (1986, p. 474), pois revela o drama do urbanismo moderno que, justamente em decorrência dessa excessiva tentativa de antecipação das práticas sociais, realiza "apenas a segunda parte do seu papel: a racionalização, mais ou menos incompleta, truncada, ou falida, das tendências dominantes da sociedade”. Essa antecipação contida numa planta urbana é também uma interpretação do mundo: tanto das expectativas de racionalização existentes nas apropriações contidas nos projetos quanto dos limites impostos à sua realização.

As distâncias entre expectativas e experiências, no que diz respeito à construção de Goiânia, podem ser identificadas nos relatórios preliminares, que demonstram o conhecimento das limitações estruturais do governo do estado de Goiás à época, bem como a influência política no processo de escolha do sítio para a instalação da nova capital. Ao apostar na transferência da capital goiana como um mecanismo promotor de mudanças na realidade socioeconômica do estado, tais relatórios permitem recuperar as escolhas e apropriações executadas no processo de construção da nova capital. A partir delas, pode-se considerar a identidade moderna da cidade de Goiânia por meio: 1) das adaptações dos modelos clássicos, executadas pelo seu projetista, com fins estruturais e políticos; 2) da opção por uma identidade arquitetônica capaz de lidar com recursos públicos reduzidos, sem abrir mão da unidade estética, bem como do potencial de enraizamento das opções estéticas dos projetistas na população local.

\section{As condições existentes}

O processo de escolha e transferência da capital goiana caracterizou-se por sua parcimônia e simplicidade. Isso não quer dizer, necessariamente, desleixo ou despreocupação com o empreendimento a ser realizado; indica, sim, o respeito às condições estruturais pelas quais passava o estado de Goiás, que possuía recursos limitados. Como demonstra 
a Tabela 1 abaixo, a arrecadação estadual goiana no início do processo de construção da nova capital não atingia a metade da arrecadação do governo de Minas Gerais no início da construção de Belo Horizonte. ${ }^{1}$

TABELA 1 - Quadro comparativo entre a evolução da arrecadação estadual de Goiás e Minas Gerais, nos períodos que compreendem os processos de construção de suas novas capitais

\begin{tabular}{|c|c|c|c|}
\hline \multicolumn{2}{|c|}{ Goiás } & \multicolumn{2}{c|}{ Minas Gerais } \\
\hline Exercício & Arrecadação & Exercício & Arrecadação \\
\hline 1927 & $5.141: 323 \$$ & 1890 & $5.477: 886 \$ 685$ \\
\hline 1928 & $5.971: 052 \$$ & 1891 & $11.621: 784 \$ 636$ \\
\hline 1929 & $5.450: 754 \$$ & 1892 & $16.448: 928 \$ 797$ \\
\hline 1930 & $4.961: 020 \$$ & 1893 & $15.564: 606 \$ 411$ \\
\hline 1931 & $6.396: 689 \$$ & 1894 & $19.792: 382 \$ 600$ \\
\hline 1932 & $7.014: 201 \$$ & 1895 & $21.288: 024 \$ 467$ \\
\hline 1933 & $6.727: 489 \$$ & 1896 & $19.696: 432 \$ 971$ \\
\hline 1934 & $7.905: 193 \$$ & 1897 & $20.456: 009 \$ 366$ \\
\hline 1935 & $9.600: 835 \$$ & 1898 & $18.274: 820 \$ 986$ \\
\hline 1936 & $10.811: 669 \$$ & 1899 & $18.576: 331 \$ 931$ \\
\hline 1937 & $14.174: 700 \$$ & 1900 & $14.768: 583 \$ 962$ \\
\hline
\end{tabular}

Fonte: Teixeira (1933, 1939), Resende (1982).

Além dos recursos limitados, que geraram pedidos de empréstimos ao Governo Federal, outros dois fatores explicam a diferença do processo preparatório para a construção das duas capitais. ${ }^{2}$ Em primeiro lugar, a conjuntura política: se no caso mineiro o contexto da transferência da capital está relacionado com as disputas internas em relação à sua localização, o contexto goiano situa-se num outro extremo. Desde 1930 o estado de Goiás passa a ser governado por Pedro Ludovico Teixeira: como interventor federal nomeado por Getúlio Vargas, depois como governador eleito em 1933 e confirmado no poder em 1937, após a decretação do Estado Novo. Esse longo domínio do Executivo possibilitou a dispensa das necessárias articulações políticas em um ambiente democrático e o processo de eliminação das dissidências. Em segundo lugar, a dimensão pouco ambiciosa do projeto da nova capital do estado de Goiás em relação ao projeto da cidade de Minas. Com índices demográficos bastante inferiores aos de Minas Gerais, que contava em 1892 com 3.312.000 habitantes e em 1897, com 3.643.000 habitantes (Resende, 1982), o estado de Goiás 
registra em 1920 o número de 519.919 habitantes e em 1940, 826.414 habitantes (Machado, 1990). Até 1920 a cidade mais populosa no estado de Goiás era Catalão, localizada no sudeste goiano, com 38.574 habitantes. A Cidade de Goiás, então capital, era a quarta maior cidade, contando, nesse mesmo ano, com 21.223 habitantes.

Em 1932, na cidade de Bomfim, o interventor já declarava publicamente sua intenção de mudar a capital. No ano seguinte, começou a mobilizar verbas para a construção e nomeou a Comissão Examinadora das Localidades, que deveria realizar o exame e a escolha do sítio mais propício para o estabelecimento da nova capital (Goiás, 1932). ${ }^{3}$ Alguns sítios foram previamente selecionados por um dos membros da comissão, Colemar Natal e Silva, que elegeu um critério geopolítico: o sul do estado, nas proximidades da estrada de ferro, visto que "quanto ao norte acredita o orador que ele jamais possa se articular com o sul, por causa mesmo de sua situação geográfica, sendo de notar que ele não mantém nenhum comércio com a velha capital" (Monteiro, 1979, p. 34). Nos relatórios subsequentes, essa argumentação será reforçada. Neste sentido, a nova cidade não seria uma capital para o estado, e sim para o sul do estado (Campos, 1983; Palacin, 1991).

Quatro localidades foram selecionadas: Bomfim, Ubatan, Campinas e Pires do Rio. Os requisitos a serem observados nas localidades obedeciam a critérios relativamente comuns às concepções urbanísticas do período: abundância de água, bom clima e topografia adequada (Monteiro, 1979, p. 34). Há que se perceber a pouca alusão a instrumentos e referências técnicas que possibilitassem estabelecer os parâmetros de comparação para as conclusões adotadas no relatório das localidades. Pelo contrário, a base para tais observações foi a autoridade política do presidente da Comissão. O mesmo procedimento parcimonioso foi utilizado no exame das outras localidades. A cidade de Pires do Rio foi descartada por razões de ordem topográfica:

A posição topográfica mais bela e adequada daquela localidade foi ocupada pela atual cidade, cujo traçado, de modo bastante lamentável, não obedece tecnicamente às linhas que a topografia local ofereceria à estética e ao aproveitamento econômico de seu escoamento. (Monteiro, 1979, p. 40)

Em relação à cidade de Ubatan, o relatório descarta-a em meia página, por não apresentar boas condições de potabilidade da água e ter 
topografia demasiadamente plana. Quanto a Campinas, “oferece todos os requisitos topográficos indispensáveis para a construção de uma linda cidade moderna e salubérrima" (Monteiro, 1979, p. 42).

Dois elementos chamam ainda a atenção no processo de escolha do sítio para a nova capital do estado de Goiás. Entre todos os locais pesquisados, apenas Campinas parece ter recebido, por parte da Comissão Examinadora, uma atenção maior. Trechos do relatório da Comissão, conforme mostra Monteiro (1979, p. 42-43) são reveladores da situação daquele sítio, não como pleiteante, e sim como futura capital: "A posição mais apropriada para a construção da nova capital se acha no rumo 130 (cento e trinta) graus de Campinas e a mais ou menos sete quilômetros de distância"; "chegamos à conclusão de que o reservatório d'água potável para o abastecimento da cidade deverá ser construído no morro da 'Serrinha"; "verificamos que o escoamento da cidade a construir-se deverá ser para os rios Santo Antônio ou Meia Ponte, dependendo da escolha, de levantamentos que possam determinar a maior economia"; "nesse rio existe a corredeira [...] podendo fornecer uma fôrça hidráulica efetiva [...] que poderá vantajosamente ser aproveitada enquanto o permitir o desenvolvimento inicial da nova capital”. Neste caso, a perspectiva do possível é substituída pela certeza do futuro.

Um segundo indício importante está na aposição de outro critério para a candidatura de Campinas: a sua proximidade dos trilhos da estrada de ferro, que chegava a Bomfim. Não é possível determinar a influência de Laudelino Gomes, então chefe do Serviço Sanitário do Estado, sobre a decisão tomada, muito embora ele haver declarado que a nova capital seria construída no município de Campinas (A Informação Goyana, 1932), antes mesmo de a comissão para a escolha das localidades ter sido nomeada e da qual ele faria parte.

Feita a escolha de Campinas como sede da nova capital, o relatório final, assinado no dia 4 de março de 1933, sugeria ao governador, contudo, o parecer de outro técnico, “de projeção nacional, e internacional”. A sugestão foi acatada e em 24 de abril do mesmo ano, o engenheiro Armando Augusto de Godoy envia ao interventor federal o Relatório sobre a conveniência da mudança da capital. É a partir desse relatório que começam a ser percebidas as concepções que dominarão o projeto da nova capital do estado de Goiás. 
Nesse documento, as escolhas realizadas pela Comissão são confirmadas após o exame in loco do sítio selecionado e organizado a partir de uma série de temas associados às características da cidade moderna. Dentre elas, destaca-se a sua função pedagógica, que "educa as massas populares, compõe-lhes e orienta-lhes as forças e os movimentos coletivos e desperta energias extraordinárias entre os que aí vivem e ficam sob a sua influência civilizadora" (Monteiro, 1979, p. 50). É a partir dessas expectativas sobre a cidade nova que Godoy avalia a escolha de Campinas para ser o sítio da nova capital. Ao mesmo tempo, o engenheiro reforça o caráter político da transferência: "O referido local é como que o centro de gravidade da mencionada zona, de onde provêm os recursos e os elementos de vida do Estado. Tal circunstância é de fato de grande peso e devia ter atuado fortemente para a decisão final” (Monteiro, 1979, p. 60).

Ao retomar o tema da centralidade, Godoy alinha seu discurso com o projeto político do interventor. Neste sentido, em que pese seus conhecimentos técnicos, é justamente em função deles que seu relatório tem a função de confirmar, e não de examinar, a decisão politicamente dirigida da comissão. Daí a análise superficial do sítio, baseada tão somente na observação do local, na coleta de informações orais e na dispensa de visita aos outros sítios: é que as bases do consenso não estavam atreladas ao conhecimento técnico (legítimo), e sim ao conhecimento das relações de força preexistentes (dominantes).

Essa descrição da nova capital, também constante no relatório de Atílio Correa Lima de 1935, fornece alguns indícios sobre o tipo de cidade e, portanto, sobre o tipo de configuração e interpretação de mundo que moviam as expectativas dos projetistas da nova capital. Assim como a visão expressa no relatório de Armando de Godoy, Atílio Correa Lima vinculou o nascimento de um novo núcleo urbano à ideia de dinamização socioeconômica. Seu discurso, porém, foi mais adiante, ao caracterizar, a partir de termos dicotômicos, a nova e a velha capital. "Movimento excepcional" e "energias goianas" opõem-se aos termos "mentalidade perniciosa" e "aldeia". Essa dicotomia foi reforçada pela maneira incisiva como o urbanista demonstrou a necessidade de mudança. O caráter pejorativo da velha capital estava relacionado tanto ao espaço - não importa o sítio para onde se mude a capital, o importante é tirá-la de onde está - quanto ao tempo que representava - do isolamento e atraso social típico de uma mentalidade rural. A mudança da capital era, segundo esses documentos, 
uma necessidade política e uma oportunidade única para o urbanismo moderno provar seu caráter estruturador da vida em comunidade.

Urbanismo moderno: duas lições

A observação do esboço original da planta da nova capital do estado de Goiás possibilita identificar as principais matrizes urbanísticas que influenciaram o trabalho de Atílio Correa Lima. ${ }^{4}$ Mas em vez de destacar as filiações modernistas do plano urbanístico de Goiânia, destaco duas apropriações que demonstram a originalidade das soluções encontradas pelo projetista:

Primeiro - A apropriação pode ser percebida pela preocupação com a topografia. Como se pode observar no traçado criado pelo urbanista, na região leste da cidade foi projetado um tipo de estrutura viária adaptada ao relevo inclinado em direção ao córrego Botafogo. A ideia fundamental pensada pelo urbanista era de aproveitamento máximo das condições impostas pelo relevo. Daí porque, observando o sítio pré-determinado pela Comissão Examinadora das Localidades, o urbanista optou imediatamente pelo deslocamento do local para assentamento do núcleo inicial, em função da menor declividade do terreno. Esse deslocamento tinha também outra função: aproximar a malha urbana original da estrada de rodagem que dava acesso a Campinas. "Sendo a estrada a artéria vivificadora do organismo urbano, tudo indicava que o núcleo central devia ser atravessado por aquela" (Monteiro, 1979, p. 137). Dada a indicação de crescimento no sentido oeste, contida no relatório de Atílio, e a incorporação da cidade de Campinas ao município de Goiânia como futura "cidade-satélite”, chega-se à conclusão de que, após a ocupação do núcleo central, a região no entorno da estrada que ligava Goiânia a Campinas deveria constituir a zona de ocupação obrigatória.

Essa disposição de condicionar o núcleo original da cidade à única via de acesso próxima e ao terreno é constantemente encontrada no relatório apresentado por Atílio Correa Lima. Suas vias foram elaboradas de forma a não contrariar a topografia do sítio, sendo feitas "com a preocupação de não seguirem o maior declive, salvo nas avenidas e ruas principais", de modo a aproveitá-la em seu favor. "Da topografia tiramos partido também para obter efeitos perspectivos, com o motivo principal da cidade, que é o centro administrativo. Domina este a região e é visto de todos 
os pontos da cidade e principalmente por quem nela chega" (Monteiro, 1979, p. 140). Sobre essa dupla opção, Bruand (1981, p. 350) observa que "o traçado adotado favoreceu em todos os lados a evacuação pela gravidade dessas águas e dos esgotos que as recolhiam para lançá-las em coletores gerais situados no fundo dos vales".

Essa última observação nos leva à segunda característica do projeto de Atílio, já que a topografia também foi utilizada como uma função estética na elaboração da concepção geral do plano urbano, que tinha como ideia central a construção de uma perspectiva monumental, que procurava subordinar o sistema de vias a espaços de poder, fortalecendo a dimensão monumental da cidade (Arrais, 2010). A escolha de Atílio para a elaboração da região central da nova capital goiana recaiu sobre o plano radial-concêntrico, utilizado desde o Renascimento e o Barroco como elemento-chave nos grandes projetos de embelezamento das cidades europeias.

O traçado radial-concêntrico que domina a parte central da cidade é definido pelas três principais avenidas que formam a figura de um triângulo, que tem como um de seus vértices o centro administrativo, segundo a tradição de Versalhes, mas também levando em consideração o tráfego de veículos e os principais eixos de comunicação e comércio da nova cidade. O centro administrativo foi projetado para conter apenas o tráfego local, apesar da sua proximidade com o centro urbano. Esse deslocamento seria favorecido também pela malha urbana do Setor Sul - que adapta a estrutura ortogonal clássica à declividade do terreno, ao mesmo tempo em que as vias de sentido Leste-Oeste obedecem à projeção de círculos concêntricos a partir da praça central, formando um desenho em candelabro -, que canalizaria o trânsito rápido, junto com a avenida Paranaíba, e preservaria a excentricidade do centro administrativo da nova capital.

Segundo - A escolha do estilo arquitetônico foi outra estratégia de adaptação importante. Tendo em vista a impossibilidade de gastos vultuosos na construção de prédios públicos, já em 1933 Armando de Godoy lembrava em seu relatório uma solução: "Um edifício não precisa ser construído com materiais caros para se impor à administração geral, sob o ponto de vista estético. A beleza de uma construção está na relação das suas diferentes partes e na distribuição de seus volumes" (Monteiro, 1979, p. 52). Ao mesmo tempo, era necessário enfatizar o contraste entre o antigo e o moderno, entre a velha e a nova capital do estado, abrindo 


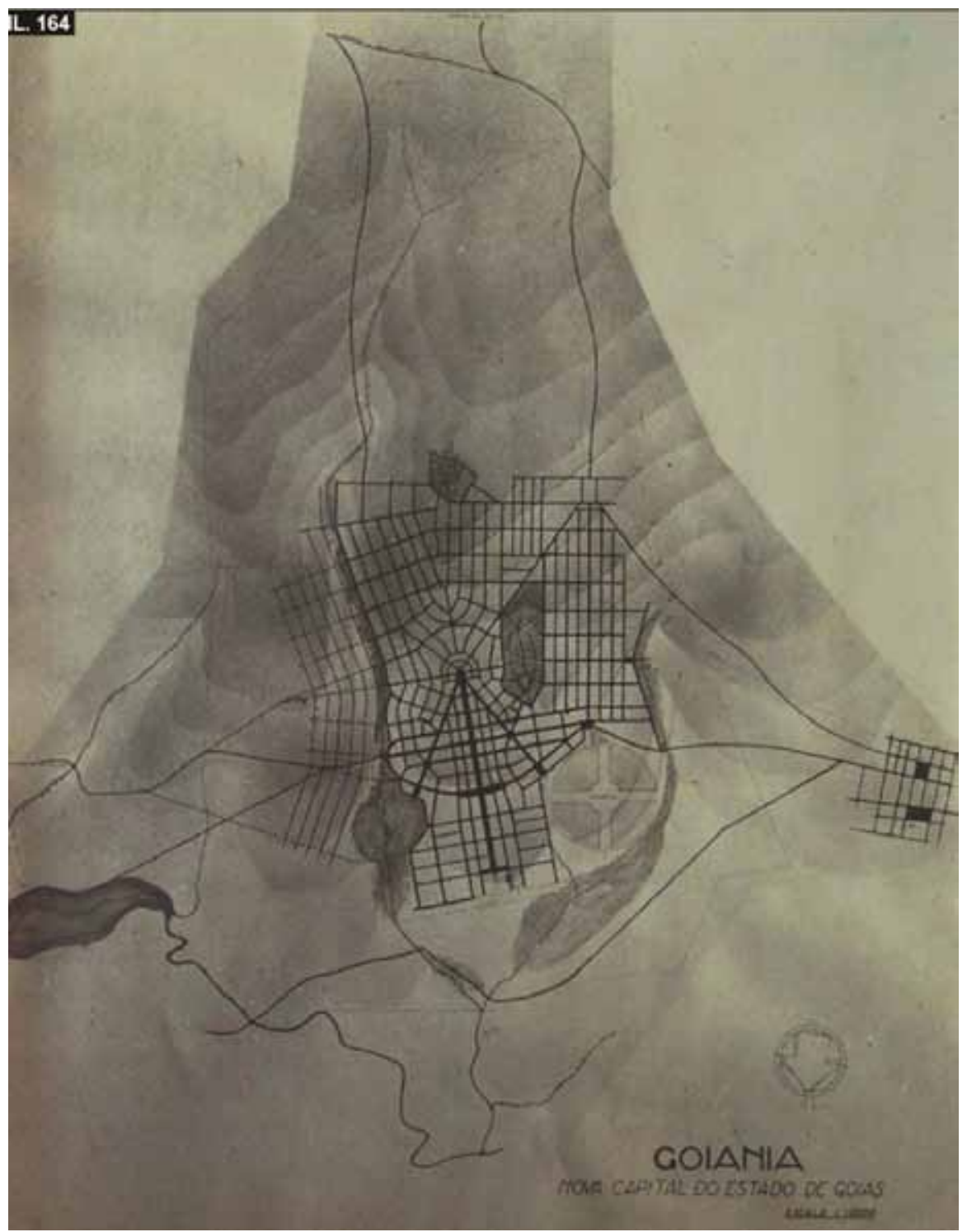

FIGURA 1 - 0 plano de Goiânia desenvolvido por Atílio Correa Lima a partir de 1933. Observa-se na parte sul uma estrutura em candelabro, que posteriormente foi modificada. Fonte: Pires (2006). 
espaço para o novo modelo de vida urbana que os urbanistas esperavam instalar na nova capital.

Mello (1996) aponta as três principais orientações arquitetônicas implantadas nas primeiras edificações da nova capital: o art déco, o neocolonial e as casas-tipo. A orientação mais divulgada e adotada nos prédios públicos foi o art déco, que tem como uma de suas características principais a recorrência aos elementos da cultura local como mecanismo individualizador da composição artístico-arquitetônica, como pode ser observada nas decorações de flamingos em Miami Beach, examinadas por Capitman (1988). No caso de Goiânia, essas figuras tiveram, além da conotação regionalista, uma dimensão histórica. Nos vitrais dos edifícios da praça central foram cuidadosamente desenhadas figuras representativas do contexto sócio-histórico regional, tais como índios, colonizadores portugueses, a economia do ouro e agropastoril etc. Segundo Manso (2004, p. 53),

Ao propor que cada região se apresente ao mundo - com suas coisas, sua gente, seus bichos e plantas, o art déco busca o melhor de cada um. Ao propor uma moldura única e uniforme para essa apresentação, o art déco promete a cada região o cosmopolitismo, não importa quão distante ela seja dos grandes centros, não importa o quão desconhecida ela tenha sido até então. Pois cada região, por minúscula e desconhecida, torna-se centro do globo, torna-se o exemplo que todas as outras querem seguir.

Esse anseio de compartilhar os valores cosmopolitas expresso no art déco influenciou a concepção de cidade dos arquitetos e engenheiros contratados para tocar as obras da nova capital e também exerceu forte impressão na população local. Para Unes (2001), a adoção do art déco como concepção padrão dos edifícios públicos teve um impacto inesperado entre os habitantes de Goiânia e de Campinas. Ela tornou-se objeto de contemplação e cópia para artesãos, mestre de obras ou pedreiros que

após observarem os novos e monumentais edifícios da nova capital, tentavam reproduzir em suas obras aqueles frisos, ornatos ou o coroamento. Esses artesãos agiam por imitação, fosse por iniciativa própria - o que é mais provável - fosse a pedido do proprietário-consumidor. Ao adornar um barracão de taipa ou mesmo de adobe com um imponente zigurate na platibanda, ao dar a forma quadrada ao capitel de um pilar, o mestre-de-obra fechava a ponta de um círculo estilístico que realizava troca de influências numa escala planetária pela primeira vez na história. (Unes, 2001, p. 130-131) 
a)

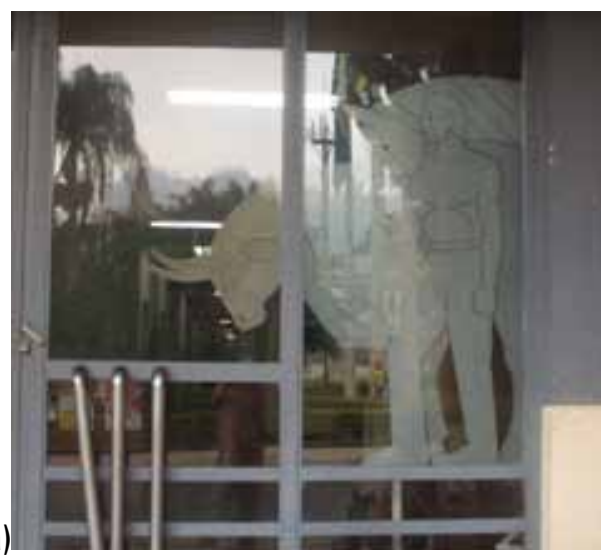

b)

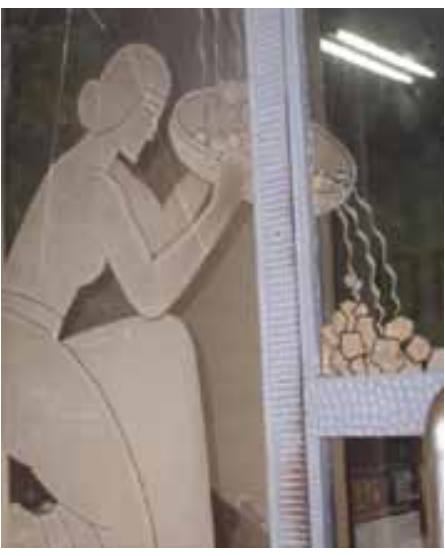

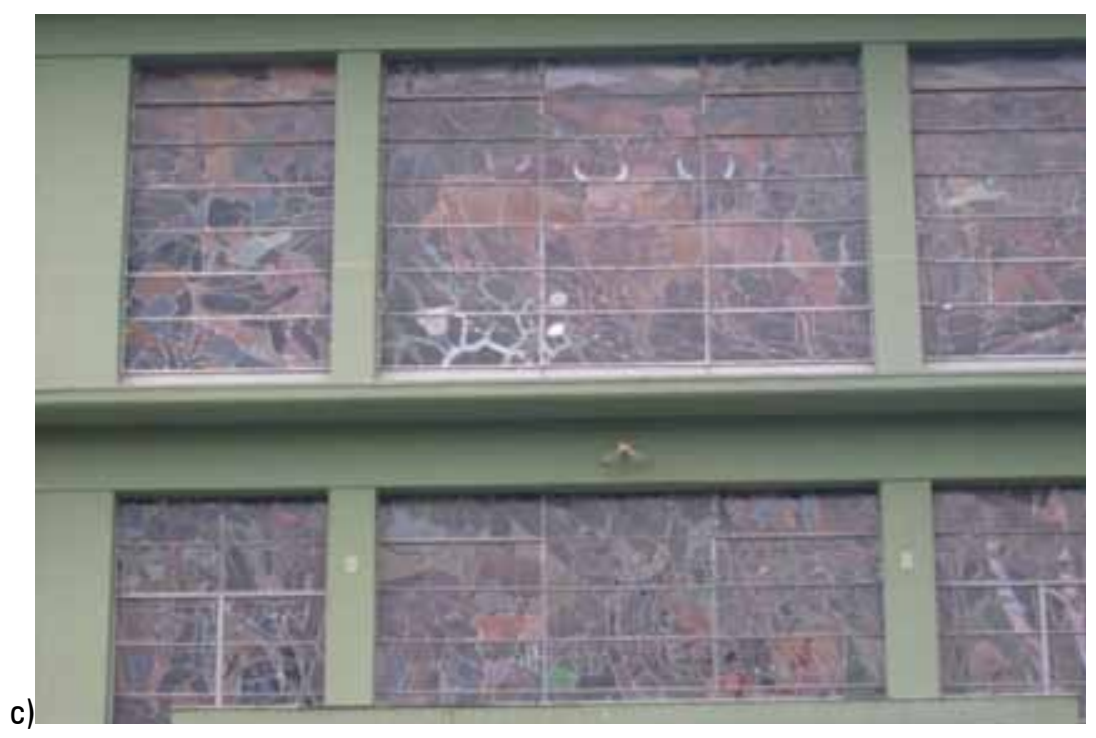

FIGURA 2 - Detalhes dos vitrais dos edifícios públicos da praça central: a) a criação de gado, base da economia goiana na época da construção de Goiânia; b) a extração de ouro que deu origem à colonização da região; c) na frente do palácio do governo, um vitral narrando a história de Goiás e de suas principais riquezas.

Fonte: Acervo do autor.

Aquilo que o autor chama de imitação é, na verdade, uma importante característica do processo de apropriação dos modelos culturais, tão criativa quanto aquela executada por Atílio Correia Lima. Isso porque 
esses trabalhadores tiveram de adaptar essas novas referências às deficiências estruturais de uma cidade com recursos escassos e com tecnologias construtivas predominantemente tradicionais durante os primeiros anos. A ênfase ornamental, em muitos casos localizada nos detalhes das fachadas, adequou-se ao programa construtivo dos construtores da nova capital, incorporando as intenções cosmopolitas à cultura interiorana.

Desde o início da década de 1940, estruturou-se uma rede de sociabilidade entre a elite local, que acabou por estabelecer um aprendizado mútuo, sustentado por atividades culturais consideradas eruditas ou pertencentes à alta cultura. "Nos grandes países civilizados", anotava um folheto de divulgação de uma escola de dança, "há cursos obrigatórios de dança clássica nas escolas. O Brasil deveria tomar este maravilhoso exemplo, abrir cursos de 'ballet' em todos os centros culturais, divulgando a necessidade desta aprendizagem para a melhoria da nossa raça" (Schifino, 2012, p. 118). A dança, nesse sentido, foi utilizada como ferramenta de difusão dos valores sociais e políticos da elite local, moldando aquilo que à época era considerado o comportamento aceitável. Ela destinava-se a complementar "a formação cultural que todo jovem moderno necessita [...] permite corrigir o porte e a postura” (Schifino, 2012, p. 69). Indivíduos/ grupos alimentam-se desse habitus, que por sua vez utiliza a dança como critério de recrutamento, formação e socialização da elite local.

\section{Considerações finais}

Chamada a prestar contas com os vestígios do passado, a historiografia goiana encontra diante de si um problema de ordem heurística, na medida que toma como verdadeira a ideia de modernidade, sem levar em consideração que as expectativas projetadas nos relatórios não podem ser tomadas como expectativas realizadas. Relatórios e projetos indicam, sem sombra de dúvida, os vínculos com a modernidade europeia que, afinal, foi o ambiente acadêmico de formação de Atílio Correa Lima. Há que se perceber, porém, que naquilo que concerne à modernidade do projeto urbanístico de Goiânia, sua identidade está muito menos associada aos modelos das cidades citadas e muito mais nas apropriações realizadas pelos projetistas da nova capital goiana; muito menos na cópia e muito mais na originalidade das soluções encontradas para lidar com o urbanismo no sertão. 
Por isso, é preciso ressaltar que, malgrado o purismo conceitual, aquilo que é muitas vezes interpretado como desequilíbrio, frustração, deturpação e farsa revela na verdade o caráter plural e potencialmente criativo da modernização brasileira, capaz de engendrar soluções novas, próprias do seu processo histórico.

Como uma verdadeira aula de urbanismo, o projeto original de Goiânia pode ser relacionado a concepções arquitetônicas e urbanísticas variadas, tais como o traçado orgânico e a citação ao barroco europeu, à cidade-jardim, ao traçado em grelha etc. Cada uma dessas referências refletiria, à sua maneira, as expectativas projetadas pelos seus projetistas e executores: a partir dos grandes modelos e das grandes experiências urbanísticas internacionais foi possível, no sertão, construir uma cidade moderna. Isso foi possível justamente porque, como lembra Giulio Carlo Argan (1995), nenhuma cidade possui um sentido pré-definido. São os homens que atribuem valor às pedras, "e todos os homens, não apenas os arqueólogos ou os literatos [...] De fato, o valor de uma cidade é o que lhe é atribuído por toda a comunidade” (Argan, 1995, p. 228-229).

\section{Notas}

1. É preciso notar a distância temporal que separa os dois processos e sua sujeição às conjunturas de instabilidade econômica nacional e regional nos referidos períodos. No caso mineiro, a política de encilhamento praticada pelo governo federal e a desvalorização do café levaram a um decréscimo significativo da receita estadual e interferiram diretamente na condução do processo construtivo de Belo Horizonte. No caso goiano, apesar do seu crescimento relativamente contínuo, a arrecadação foi prejudicada pela passagem da Coluna Prestes pelo estado de Goiás e pela Revolução de 1930.

2. Foram concedidos pelo Governo Federal 5.663:000\$000 em apólices, em 1936, além de mais 3.000:000\$000 por Getúlio Vargas e outros 1.200:000\$000 em empréstimos externos. Até 1935 a venda de lotes da nova capital havia rendido aos cofres públicos a soma de apenas 879:377\$097. Cf. Monteiro, 1979.

3. A comissão foi formada por oito pessoas: o bispo de Goiás, D. Emanuel Gomes de Oliveira, um advogado, Colemar Natal e Silva; um oficial superior do exército, Cel. Pireneus de Sousa; um médico chefe do Serviço Sanitário do Estado, Laudelino Gomes; dois comerciantes, Antônio Santana e Gumercino Ferreira; e dois engenheiros, Jerônimo Curado Fleurí e João Argenta, este funcionário do Estado. Todos, com exceção do último, sem remuneração.

4. Não é difícil identificar as tendências racionalistas e funcionalistas na cidade planejada por Atílio Correa Lima. É duvidoso, entretanto, identificar o projeto de Goiânia com as propostas da Carta de Atenas, de Le Corbusier, como faz, 
por exemplo, Bernardes (2000). Isso porque os próprios preceitos da Carta de Atenas só foram publicados em 1942 por Le Corbusier. Mesmo as versões do Congresso Internacional de Arquitetura Moderna, da qual a Carta de Atenas é uma interpretação unilateral de Le Corbusier, ainda não possuía, no início da década de 1930, uma sistematização. Por último, as tendências teóricas de Atílio e Godoy estão mais próximas de Agache - com quem trabalharam - do que de Le Corbusier. Da mesma maneira, Goiânia não pode ser compreendida como uma prefiguração de Brasília, como afirma Bruand (1981). Apesar de o projeto da nova capital goiana já apresentar traços modernistas e soluções próximas àquelas que seriam aplicadas em Brasília, a tese do projeto de Goiânia como gênese do projeto de Brasília carece de comprovação empírica. As filiações urbanísticas do projeto de Goiânia foram exaustivamente trabalhadas em outros estudos, muito embora esse trabalho comparativo acabe por reduzir o trabalho de Atílio, ressaltando o padrão (Versalhes, cidade-jardim etc.), em vez da inovação. Cf. Cordeiro, 1989; Cordeiro e Queiroz, 1980; Daher, 2003.

\section{Referências}

A INFORMAÇÃO GOYANA, dez. 1932.

ARGAN, G. C. A história da arte como história da cidade. São Paulo: Martins Fontes, 1995.

ARRAIS, C. A. Monumentalidade, linhagem e estrutura narrativa: um estudo sobre o horizonte de expectativa do projeto urbanístico de Goiânia. ArtCultura, v. 12, n. 21, 2010.

BERMAN, M. Tudo o que é sólido desmancha no ar. São Paulo: Companhia das Letras, 1987.

BERNARDES, G. Considerações sobre o plano de Goiânia. In: SILVA, L. S. D. (Org.). Relações cidade - campo: Fronteiras. Goiânia: Ed. UFG, 2000.

BRUAND, Y. Arquitetura contemporânea no Brasil. São Paulo: Perspectiva, 1981.

CAMPOS, F. I.. Coronelismo em Goiás. Goiânia: Cegraf, 1983.

CAPITMAN, B. B. Deco delights: preserving Miami Beach architecture. New York, USA: E.P. Dutton, 1988.

CORDEIRO, N. A. Goiânia: evolução do plano urbanístico. Goiânia: Seplan, 1989.

CORDEIRO, N. A.; QUEIROZ, N. M. Embasamento do plano urbanístico original. Goiânia: Cartográfica, 1980.

DAHER, T. Goiânia: uma utopia européia no Brasil. Goiânia: ICBC, 2003.

GOIÁS (Estado). Decreto n. 2737 de 20 de dezembro de 1932. Dispõe sobre a criação da comissão que irá escolher o local onde será construída a nova capital de Goiás.

MACHADO, M. C. T. Pedro Ludovico: um tempo, um carisma, uma história. Goiânia: Cegraf, 1990.

MANSO, C. F. A. (Org.). Goiânia art déco: acervo arquitetônico e urbanístico dossiê de tombamento. Goiânia: Seplan, 2004. 
MELLO, M. M. Moderno e modernismo: a arquitetura dos dois primeiros fluxos desenvolvimentistas de Goiânia. Dissertação (Mestrado em Arquitetura e Urbanismo) - Faculdade de Arquitetura e Urbanismo - Universidade de São Paulo, São Paulo, 1996.

MONTEIRO, O. S. N. Como nasceu Goiânia. São Paulo: Revista dos Tribunais, 1979.

PALACIN, L. Coronelismo no extremo norte de Goiás. Goiânia: Cegraf, 1991.

PIRES, J. R. Goiânia: La ciudad pré-moderna del cerrado. Tese (Doutorado em Arquitetura) - Universitat Politecnica de Catalunya, Barcelona, Espanha, 2006.

RESENDE, M. E. L. Formação da estrutura de dominação em Minas Gerais: o novo PRM (1889-1906). Belo Horizonte: Fundação João Pinheiro, 1982.

RONCAYOLO, M. Cidade. Enciclopédia Einaudi, v. 8. Lisboa, Portugal: Imprensa Nacional/Casa da Moeda, 1986.

SCHIFINO, R. B. Uma perspectiva histórica sobre a constituição da dança em Goiânia (1940-1990). Dissertação (Mestrado em História) - Faculdade de História, Universidade Federal de Goiás, Goiânia, 2012.

SILVA, L. S. D. A construção de Brasília: modernidade e periferia. Goiânia: Ed. UFG, 1997.

TEIXEIRA, P. L. Relatório apresentado ao Exmo. Sr. Dr. Getúlio Vargas, DD. Chefe do Governo, e ao Povo Goiano, 1933. In: MONTEIRO, O. S. N. Como nasceu Goiânia. São Paulo: Revista dos Tribunais, 1979.

TEIXEIRA, P. L. Relatório enviado ao Exmo. Sr. Presidente da República pelo Dr. Pedro Ludovico Teixeira, Interventor Federal em Goiás, 1939. In: MONTEIRO, O. S. N. Como nasceu Goiânia. São Paulo: Revista dos Tribunais, 1979.

UNES, W. Identidade art déco de Goiânia. Goiânia: Ed. UFG, 2001.

Cristiano Alencar Arrais - Doutor em História pela Universidade Federal de Minas Gerais - Professor da Universidade Federal de Goiás. 